\author{
Б. В. Борц ${ }^{1}$, С. Ф. Скоромная ${ }^{1}$, \\ В. И. Ткаченко ${ }^{1,2}$ \\ ${ }^{1}$ ННЦ «Харьковский физико-технический институт» \\ НАН Украины, г. Харьков, Украина \\ ${ }^{2}$ Харьковский национальный университет \\ имени В. Н. Каразина, г. Харьков, Украина
}

\section{Извлечение урана}

\section{из материалов}

\section{техногенных месторождений методом сверхкритической флюидной экстракции}

Представлены разработанные в ННЦ ХФТИ метод и установка сверхкритической флюидной экстракции в среде диоксида углерода комплексов урана. Исследована эффективность экстракции комплексов урана из гранитов, которыми моделировались урансодержащие материалы техногенных месторождений. Показано, что при определенных параметрах экстракции можно достичь высоких коэффициентов извлечения комплексов урана из исходных материалов. Сделан вывод о перспективности разработанного метода для использования в технологии извлечения комплексов урана из техногенных месторождений.

К лю че в ы е сл о в а: сверхкритическая флюидная экстракция, диоксид углерода, граниты, трибутилфосфат, Арсеназо-ІІІ.

\section{Б. В. Борц, С. Ф. Скоромна, В. І. Ткаченко}

Вилучення урану з матеріалів техногенних родовищ методом надкритичної флюїдної екстракції

Представлено розроблені в ННЦ ХФТІ метод іустановку надкритичної флюїдної екстракції в середовищі двоокису вуглецю комплексів урану. Досліджено ефективність екстракції комплексів урану згранітів, якими моделювались уранутримуючі матеріали техногенних родовищ. Показано, що за певних параметрів екстракції можна досягти високих коефіцієнтів вилучення комплексів урану з вихідних матеріалів. Зроблено висновок щодо перспективності розробленого методу для використання в технології вилучення комплексів урану з техногенних родовищ.

Ключов і слов а: надкритична флюїдна екстракція, двоокис вуглецю, граніти, трибутилфосфат, Арсеназо-ІІІ.

(C) Б. В. Борц, С. Ф. Скоромная, В. И. Ткаченко, 2011
$\mathbf{Y}$ краина входит в число стран, развивающих атомную энергетику, а также обладающих значительными запасами природного урана. Для обеспечения атомных электростанций Украины ядерным топливом собственного производства одной из актуальных задач является разработка экологически чистых методов извлечения урана из природного сырья. Новые методы в будущем позволят сделать весомый вклад в решение еще одной немаловажной задачи, связанной с утилизацией радиоактивных отходов как техногенных месторождений, так и накопленных на предприятиях ядерного топливного цикла (ЯТЦ).

Решение проблемы обеспечения украинских АЭС топливом собственного производства тесно связано с остро стоящей экологической проблемой: наличием техногенных месторождений с высоким содержанием токсичных элементов, в частности Приднепровского химического завода в г. Днепродзержинске и объектов по добыче и переработке урана в г. Желтые Воды. Эту проблему необходимо решить в кратчайшие сроки, поскольку при переработке урановых руд основная часть урана (до $90 \%$ ) переходит в раствор. Вместе с ураном растворяется небольшая часть других радиоактивных элементов, а также некоторые компоненты сопутствующих пород. При разделении образуется так называемая песковая фракция, составляющая основную часть твердых отходов, которая после промывки поступает на хвостохранилище и таким образом формирует техногенное месторождение. В Днепродзержинске расположено семь хвостохранилищ, в которых накоплено более 40 миллионов тонн отходов, содержащих радиоактивные и химически опасные вещества: уран, продукты его распада, мышьяк, селен, торий, радий и т. п. В Днепродзержинске отходы занимают площадь около $2,5 \cdot 10^{6} \mathrm{M}^{2}$ [1]. Приблизительно такую же площадь занимают хвостохранилища в г. Желтые Воды [2].

Кроме этого в Украине существует ряд промышленных регионов, в которых радиоэкологическая обстановка определяется деятельностью угольных шахт. Например, в Донбассе за 200 лет добычи каменных углей и антрацитов накоплено более 1200 терриконов общим объемом угольных пород 1056519,9 тыс. м³ ${ }^{3}$ Под терриконами занято 5526,3 га земель, пригодных для сельского хозяйства. Породные отвалы, особенно горящие, являются источниками пыли и различных токсичных соединений, что негативно сказывается на окружающей среде в регионе и вызывает необходимость использования пород терриконов в различных отраслях промышленности и сельского хозяйства [3]. Исследования отходов гравитационного и флотационного обогащения угля на содержание актинидов показало в них достаточно высокое содержание урана $(15 \div 150$ г/т) и тория $(20$ г/т) [4].

Таким образом, применение на предприятиях ЯТЦ традиционных технологий добычи и переработки урансодержащих руд с целью извлечения урана ведет к накоплению значительного количества опасных радиоактивно загрязненных веществ, что повышает риск радиационного воздействия на окружающую среду, обслуживающий персонал и население.

Разработка новых методов и технологий, которые обеспечат максимально возможное извлечение урана из радиационно-опасных веществ техногенных месторождений, будет способствовать нормализации экологической обстановки в Украине, а также позволит сделать серьезный вклад в решение проблемы обеспечения АЭС Украины ядерным топливом собственного производства. 
Методика эксперимента. В ННЦ ХФТИ разработан метод и создана экспериментальная лабораторная пилотная установка СФЭ-U для разработки технологии извлечения радионуклидов [5-8] с использованием сверхкритической

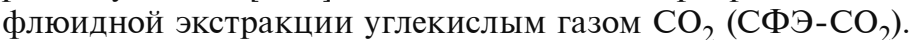

Сверхкритическая флюидная экстракция (СФЭ) - новейший, бурно развивающийся, экологически чистый, сухой метод извлечения различных материалов из сырья растительного, минерального или техногенного происхождения. СФЭ - экстракция веществами, находящимися при температуре и давлении выше критических. Наиболее часто для СФЭ используется $\mathrm{CO}_{2}$, циркулирующий в замкнутом объеме без сброса в атмосферу. Этот газ не токсичен, не активен, доступен, дешев и обладает невысокими критическими параметрами (температура более $37{ }^{\circ} \mathrm{C}$ и давление более 7,3 МПа).

В последнее время большой интерес исследователей привлекает изучение процессов сверхкритической флюидной экстракции биологических материалов (эфирные масла, биодизель и т. д.), а также комплексов металлов (бета-дикетонаты редкоземельных металлов, комплексы актиноидной группы металлов). Этот интерес обусловлен, прежде всего, тем, что экстрагируемое вещество не несет в себе никаких следов количеств экстрагента, в отличие от традиционных методов жидкостной экстракции.

Для проведения СФЭ комплексов урана и его соединений нами была спроектирована и изготовлена лабораторная пилотная установка (рис. 1).

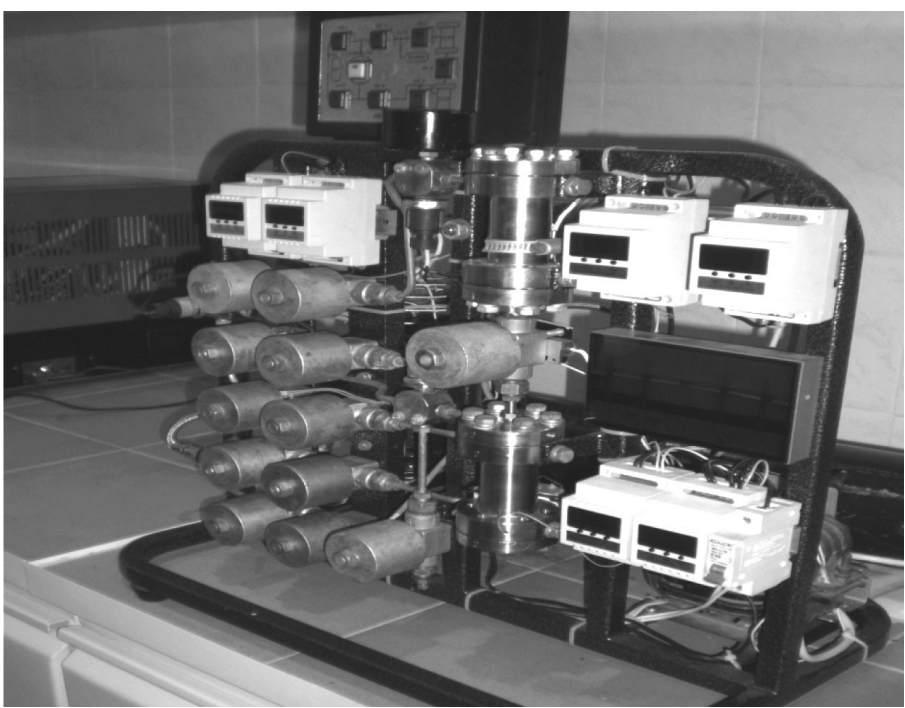

Рис. 1. Внешний вид установки сверхкритической флюидной экстракции СФЭ-U

Содержание урана в исходных материалах определялось с помощью гамма-спектрометра СЭГ-50(П) с германиевым детектором марки ДГДК-60В. Точность определения концентраций излучающих изотопов составляла $15 \%$. Для определения содержания урана на этапе пробоподготовки и определения эффективности экстракции применялись рентгеновский флуоресцентный анализатор КРАБ-ЗУМ и спектрофотометр СФ-2000 с использованием реагента Арсеназо-III. Суммарная погрешность определения количества урана в образцах для каждого метода составляла $10 \%$.

Использовались образцы гранитов из разных месторождений. Из пяти образцов гранитов были выбраны два
(№ 2 и № 4) с содержанием урана 5,5 и 3,1 мкг/г, соответственно.

Образцы гранитов дробились и измельчались в порошок с размером частиц менее 50 мкм. Порошки заливались $30 \%$-й азотной кислотой в массовом соотношении 1:1 и выдерживались в течение 24 ч. Полученный раствор смешивался с $20 \%$-м раствором трибутилфосфата (ТБФ, эфир фосфорной кислоты) в уайт-спирите и взбалтывался. После расслоения органическая фаза в количестве 1 мл наносилась на лист фильтровальной бумаги диаметром 150 мм, высушивалась для удаления растворителя и помещалась в экстракционную ячейку.

Результаты и обсуждение. Экстракция проводилась в две стадии: быстрая - образцы выдерживались при давлении 9,0 МПа и температуре $38{ }^{\circ} \mathrm{C}$ в течение 2 мин, и медленная - образцы выдерживались при давлении 18,5 МПа и температуре $45^{\circ} \mathrm{C}$ в течение 60 мин. После каждой экстракции содержимое ячейки сбрасывалось на подложку, состоящую из пяти пронумерованных бумажных фильтров. Осажденное вещество каждого из пронумерованных фильтров анализировалось на рентгеновском анализаторе. Для получения спектров поглощения задержанного фильтром экстракта фильтры погружались на 10 мин в 0,005 \%-й водный раствор Арсеназо-III.
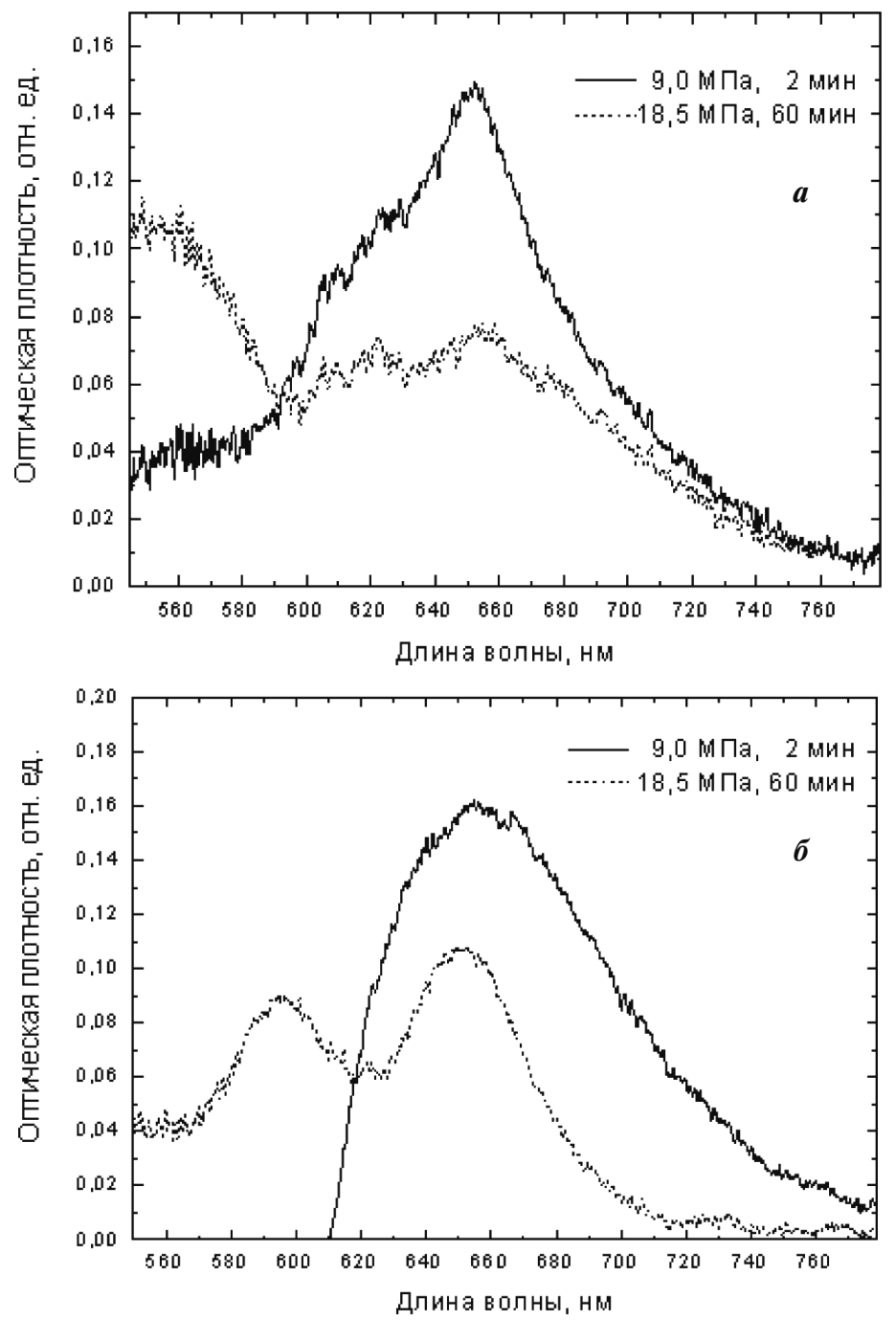

Рис. 2. Спектры оптического поглощения комплексов с Арсеназо-ІІІ продуктов СФЭ- $\mathrm{CO}_{2}$ : $a-$ образец гранита № 4; $\sigma$-образец гранита № 2 
Анализ спектров (рис. 2) поглошения комплексов Арсеназо-III с продуктами экстракции гранитов показывает, что при первой «быстрой» экстракции извлекается основная часть комплекса урана. Вид спектра поглощения (сплошная кривая на рис. 2 с характерной резонансной полосой 661 нм) совпадает с эталонным спектром поглошения комплекса Арсеназо-ІІІ - уранилнитрат [9], что указывает на тот факт, что уран в экстракте находится в шестивалентном состоянии.

Из сравнения рис. $2, a$ и рис. $2, \sigma$ видно количественное различие в спектрах поглощения результатов «быстрой» и «медленной» экстракций. По-видимому, вариации давления и температуры приводят к изменению эффективности извлечения отдельных компонентов исходного материала, в результате чего примеси других элементов экстрагируются в ТБФ и дают дополнительные цветовые реакции с Арсеназо-III.

В табл. 1 приведены результаты СФЭ из различных марок гранитов.

Таблица 1. Количество урана на фильтрах после экстракции

\begin{tabular}{|l|c|c|c|}
\hline \multirow{2}{*}{ Экстракция } & \multicolumn{2}{|c|}{$\begin{array}{c}\text { Обнаруженное } \\
\text { количесто урана, мкг }\end{array}$} & $\begin{array}{c}\text { Суммарная } \\
\text { эффектив- } \\
\text { ность, \% }\end{array}$ \\
\cline { 1 - 3 } & $\mathbf{C Ф - 2 0 0 0}$ & КРАБ-3УМ & \multirow{2}{*}{36} \\
\hline №2 «быстрая» & 10,8 & 0 & \\
\hline №2 «медленная» & 6,9 & 42 & \multirow{2}{*}{62} \\
\hline №4 «быстрая» & 10,2 & 32 & \\
\hline №4 «медленная» & 5,2 & 12 & \\
\hline
\end{tabular}

Из таблицы следует, что полученные на лабораторной пилотной установке СФЭ-U результаты экстракции комплексов урана из гранитов различных марок дают веские основания считать данный метод перспективным для переработки низкообогащенных отвалов урановой руды или техногенных месторождений.

\section{Выводы}

Первые эксперименты по сверхкритической флюидной экстракции комплексов урана из модельных материалов, в качестве которых выбраны граниты, показали: многоступенчатая экстракция может обеспечить суммарную эффективность выделения урана на уровне $62 \%$, что указывает на перспективность разработанного метода.
Проведенные исследования и полученные результаты позволяют сформулировать основные требования по давлению углекислого газа, температуре и времени экстракции лабораторной пилотной установки СФЭ- $\mathrm{CO}_{2}$ экстракции урана.

Авторы выражают благодарность С. Ю. Саенко (ННЦ ХФТИ, нач. отдела технологий обработки РАО) за обсуждение результатов, ценные замечания и проявленный интерес к работе.

\section{Список использованной литературы}

1. Тютюников, A. Урановые отходы угрожают востоку Украины // Газета 2000, 14 июля 2006, с. В5.

2. Коваленко, Г. Д. Основы радиационной экологии / Г.Д. Коваленко, В.С. Волошин // Мариуполь: изд-во «Рената», 2009. $298 \mathrm{c}$.

3. Панов, Б. С. Новые виды минерального сырья Донбасса / Б.С. Панов, Ю.А. Проскурня // Мат. наук.-практ. конф. «Донбас2020: наука і техніка - виробництво»: Донецк: ДонНТУ, 2002. C. $74-77$.

4. Петрова, Л. О. Умови формування техногенних родовищ // Наук. праці Донецького нац. техн. ун-ту. Серія: «Гірничо-геологічна». - Вип. 81. - Донецьк, ДонНТУ, 2004. - 150 с.

5. Бочаров, В. А. Особенности экстракции $\beta$-дикетонатов металлов жидким диоксидом углерода / В. А. Бочаров, О. В. Полевич, В. И. Ткаченко // Сб. тез. докл. II Междунар. науч.-практ. конф. «Научный потенциал мира 2005», 19-30 сентября 2005. T. 9. - C. $58-64$.

6. Полевич, О. В. Использование сверхкритической флюидной экстракции (СФЭ) для утилизации радионуклидов / О. В. Полевич, В. И. Ткаченко, А. В. Шперер // Сб. научн. статей XIV Международ. науч.-техн. конф. «Экология и здоровье человека. Охрана воздушного и водного бассейнов. Утилизация отходов», 5-9 июня 2006, г. Щелкино, АР Крым. - Т. 2. - С. 244-245.

7. Неклюдов, И. М. Сравнение и анализ существующих методов извлечения урана и его соединений из материалов атомной энергетики / И. М. Неклюдов, Н. А. Азаренков, Б. В. Борц и др. / Препринт, Харьков: ННЦ ХФТИ, 2008. - 62 с.

8. Бори, Б. В. Сверхкритическая $\mathrm{CO}_{2}$ экстракция комплексов урана из гранитов /Б.В. Борц, Ю.Г. Казаринов, И.М. Неклюдов и др. // Физика и химия обработки материалов. -2010 . - № 3. C. $94-96$.

9. Саввин, С. В. Органические реагенты группы арсеназо-III / С.В. Саввин. - М.: Атомиздат, 1971. -352 с. 